\title{
Source of Health Insurance Coverage and Employment Survival Among Newly Disabled Workers: Evidence from the Health and Retirement Study*
}

\author{
Matthew J. Hill \\ Nicole Maestas \\ Kathleen J. Mullen
}

RAND

September 2014

\begin{abstract}
We use prospective longitudinal data on newly disabled older workers to examine the effect of employer sponsorship of health insurance (ESHI) on post-onset employment and disability insurance claiming. We compare outcomes of workers with ESHI and no access to spousal coverage prior to onset with outcomes of two comparison groups: individuals with ESHI who also have access to spousal coverage and those who are covered by a spouse's employer prior to onset. We find evidence of "employment lock" among the 20 percent of individuals whose disabilities do not impact their immediate physical capacity but are associated with high medical costs.
\end{abstract}

\footnotetext{
"Hill: RAND Corporation, 1776 Main Street, Santa Monica, CA 90401 (e-mail: mhill@rand.org);Maestas: RAND Corporation, 1776 Main Street, Santa Monica, CA 90401 (email: maestas@rand.org); Mullen: RAND Corporation, 1776 Main Street, Santa Monica, CA 90401 (e-mail: kmullen@rand.org). We thank Sarah Kups for excellent research assistance, Orla Hayden for programming assistance, and Brandy Lipton and participants of the 2014 American Society of Health Economists Biennial Conference and RAND’s Labor \& Population brownbag seminar series for helpful comments and suggestions. This research was supported by a grant from the Alfred P. Sloan Foundation.
} 


\section{Introduction}

As an aging U.S. population causes economic and fiscal pressures to mount, there is growing policy interest in facilitating longer work lives among those who have the desire and capacity for work. Maestas and Zissimopolous (2010) illustrate how a continuation of the upward trend in labor force participation at older ages could offset some of this pressure, and highlight a role for policy in helping to ease work disincentives arising through the U.S. social insurance system. In this context, most attention to date has centered on specific disincentives associated with the Social Security retirement program, such as the age of full retirement, the earnings test or the actuarial fairness of adjustments for delayed benefit claiming. Less attention has been directed to potential reforms of a closely related program, the Social Security Disability Insurance (SSDI) program, despite the fact that the SSDI program provides an important alternative pathway to retirement for many older workers. Moreover, the DI Trust Fund reserves are projected to be depleted by 2016, almost two full decades earlier than projected depletion date of 2035 for the OASI Trust Fund (Board of Trustees, 2013). Yet, Maestas, Mullen and Strand (2013) estimate that more than a third of new SSDI beneficiaries aged 45 and older retain at least some capacity for work. There has never been a more critical time to understand the determinants of labor supply of older workers with serious health problems.

The onset of a work-limiting disability sets in motion a sequence of events that for a growing number of workers ends in early retirement from the labor force, SSDI application and, ultimately, long-term program participation. Exactly how this sequence of events plays out is not well understood. Of particular interest in light of the unfolding reforms of the Affordable Care Act (ACA) is the role of health insurance in newly disabled workers' employment and SSDI claiming decisions. An extensive literature has provided convincing evidence that health insurance-particularly employer-sponsored health insurance (ESHI) - 
plays a large role in labor supply decisions along many dimensions, including employment, hours of work and job-to-job transitions (see Gruber and Madrian (2004) for a critical review of this literature). Understanding the role of ESHI is particularly important in the context of labor supply decisions among the disabled, since SSDI only confers Medicare eligibility twenty-nine months after the beneficiary has withdrawn from the labor market due to health problems. ${ }^{1}$ Thus, “employment lock”-in which an individual continues to work when he would otherwise choose not to in order to retain health insurance through his employeris a potentially important phenomenon among the disabled. ${ }^{2}$

ESHI is currently the largest source of health insurance for Americans under age 65 and economists predict that it will remain dominant even after the ACA is fully implemented (Buchmueller, Carey and Levy, 2013). However, by creating affordable public and private health insurance options that are not tied to either employment or SSDI receipt, the ACA will permanently alter the health insurance landscape for disabled workers. The extent to which the ACA could discourage work and/or encourage new SSDI applications depends on the extent of employment lock among disabled workers prior to implementation of the ACA.

A recent strand of literature has examined the labor supply effects of different health insurance expansions and contractions as "natural experiments" that mimic features of the ACA. Maestas, Mullen and Strand (2014) estimate a significant but short-lived increase in SSDI applications (excluding concurrent applications for both SSDI and SSI) in Massachusetts compared to neighboring states following the 2006 health insurance reform on which the later ACA was

\footnotetext{
${ }^{1}$ Disabled individuals may also qualify for Supplemental Security Income (SSI), a means-tested welfare program for the disabled. The SSI program confers Medicaid benefits immediately upon entitlement.

${ }^{2}$ Following Garthwaite et al. (2014), we use the term "employment lock” to emphasize our focus on the extensive margin of labor supply, as opposed to job mobility, the traditional focus of the “job lock” literature.
} 
modeled. By contrast, Baicker et al. (2013) do not find significant changes in labor supply, or disability claiming, following the randomized rollout of a 2008 Medicaid expansion in Oregon; however, they estimate that fewer than 13\% of newly insured individuals would have had ESHI in the absence of the expansion (Finkelstein et al., 2012). Finally, Garthwaite, Gross and Notowidigdo (2014) find a large increase in full-time employment (working more than 35 hours per week), and a decrease in SSDI applications, in response to an abrupt loss of Medicaid coverage in Tennessee in 2005 compared to neighboring states. While these studies suggest that the ACA could bring about a short-run release of employment lock among the stock of disabled workers, they are less informative about how the new health insurance landscape may alter the flow of newly disabled workers out of the labor force and/or into the disability insurance system.

Only a handful of studies have examined the labor supply decisions of individuals following the onset of a significant health shock. In a pair of studies, Bradley et al. (2006, 2013) find that married women newly diagnosed with breast cancer are more likely to continue to work if they depend on their employer for health insurance than if they obtain health insurance through their spouse's employer. Tuniceli et al. (2009) also examine employment lock among cancer survivors (of both genders). Finally, Bradley et al. (2012) find evidence of employment lock among older men in the Health and Retirement Study following a variety of health shocks, including a decline in self-reported health, a new diagnosis of lung disease, cancer, stroke, diabetes, angina or congestive heart failure, and hospitalization. All of these studies use a "difference-in-differences" (DID) approach comparing the labor supply of newly sick workers with ESHI to similar individuals with a different source of health insurance (e.g., spouse's employer) and controlling for differences in unobserved selection into health insurance types by netting out differences in labor supply of healthy workers. 
In this paper we examine the role of different sources of health insurance coverage, particularly ESHI, in the labor supply and disability insurance application and claiming decisions of older workers following the onset of a health impairment that specifically limits the kind or amount of paid work one can do. Using longitudinal data from the Health and Retirement Study, we employ a DID strategy similar to the one commonly used in the prior literature to examine post-onset employment of formerly healthy working individuals. To test the hypothesis of employment lock, we compare the post-onset labor supply of individuals covered by ESHI through their own employer in the wave prior to onset (and excluding those with a working spouse whose employer offers ESHI) to the labor supply of two comparison groups: 1) individuals covered by ESHI with a working spouse whose employer offers ESHI; and 2) individuals covered by their spouse's employer. Following Bradley et al. (2013) we explore heterogeneity in employment lock by impairment severity measured using an index that we created comprised of functional limitation questions and expected medical costs using diagnosis coincident with first self report of a work disability.

We find that, prior to the ACA, obtaining health insurance through one's employer did not affect the probability of continued employment for most newly disabled individuals, but it did increase employment among the 20 percent who both largely retain their prior physical functional capacity and whose disability has high expected medical costs. At the same time, we do not find any evidence that those individuals induced to stay in the labor market by ESHI would have applied for or claimed disability insurance benefits if they had a different source of health insurance prior to disability onset. This suggests that the ACA may discourage employment among those disabled workers who particularly value health insurance and who are now able obtain insurance outside the employment relationship, but it is unlikely to lead to a sustained increase in SSDI applications, perhaps because the affected workers do not have severe enough health 
impairments to qualify for SSDI. In addition to our results on ESHI, we find that individuals with Medicaid coverage prior to disability onset are substantially less likely to work and more likely to apply for, but not necessarily receive, SSDI in the years following onset. Intriguingly, the effect of Medicaid is concentrated among women and among those with higher severity and lower cost impairments.

The rest of the paper is structured as follows. Section 2 provides background on the SSDI and SSI programs and discusses health insurance options for disabled workers. Section 3 presents our conceptual framework for understanding the labor supply and claiming decisions of the disabled. Section 4 presents our data and Section 5 introduces our empirical strategy. Section 6 presents our empirical findings on the effects of health insurance on employment and disability insurance claiming following disability onset. Finally, Section 7 concludes.

\section{Disability, Health Insurance and Employment}

In the U.S. health insurance and employment decisions often go hand in hand. However, individuals with employer-sponsored health insurance (ESHI) in particular face a difficult choice following the onset of a work-limiting health condition; they may either: 1) maintain work hours at a level above the employer's eligibility threshold for ESHI, which may be physically or

emotionally painful, or 2 ) reduce hours below the employer's eligibility threshold for ESHI, jeopardizing one's access to medical care.

Figure 1 illustrates such an individual's health insurance options depending on his labor supply decision. If his health allows him to maintain hours of work above the ESHI threshold, then he has the option of maintaining ESHI. If not, he loses ESHI. In the event he loses ESHI, he may be able to obtain ESHI through his spouse in the next open enrollment period (that is, if married to a working spouse with ESHI that extends to cover him)—as long as there are no 
pre-existing condition limitations. If spousal ESHI is not an option, he may be able to purchase health insurance coverage. If he has stopped working, he can buy time-limited private health insurance (though now at full cost) through his former employer under COBRA provisions. If he continues to work part-time, he may be eligible to purchase Medicaid coverage provided his state has a Medicaid Buy-In program, his disability is severe, and his income and assets are below strict limits. Alternatively, he may purchase health insurance on the private market, which, prior to the ACA, was often prohibitively expensive. If the option to purchase coverage is not available — due to affordability, eligibility, or the lack of a Medicaid option - then he must go without health insurance coverage.

At this point, the individual may consider applying for Social Security Disability Insurance (SSDI) or Supplemental Security Income (SSI), which confer monthly cash benefits as well as health insurance coverage through Medicare after a 29-month waiting period (SSDI) or Medicaid (SSI) upon qualification for cash benefits. The two federal programs are administered by the Social Security Administration (SSA) and use the same criteria for defining disability—inability to perform "substantial gainful activity" (SGA) by reason of any medical condition(s) expected to last at least one year (or expected to result in death). SSA operationalizes the definition of SGA by setting a monthly SGA threshold. As of 2014 the SGA threshold is $\$ 1,070$ for non-blind persons and $\$ 1,800$ for blind persons. Any individual earning more than this threshold is considered to be capable of work and therefore not eligible for benefits.

Despite the unified definition of disability, nonmedical eligibility criteria and benefit formulas differ between the two programs since SSDI is a contributory social insurance program insuring workers against the risk of disability and SSI is a means-tested welfare program for the disabled. SSDI beneficiaries must have worked 5 out of the last 10 years in order to qualify for a monthly benefit payment based on their past earnings. SSI beneficiaries, on the 
other hand, must have low countable resources and they receive a monthly benefit payment based on household structure and monthly income. Individuals may qualify for both programs simultaneously. In neither case does the benefit payment vary with characteristics or severity of the disability.

As discussed above, applicants must demonstrate that they are unable to perform “substantial gainful activity,” or earn more than \$1,070 per month. For many applicants, meeting this low earnings requirement means that they must reduce their work hours below the eligibility threshold for ESHI, if offered, and in practice many applicants play it safe by leaving employment entirely (Autor et al., 2014). Thus, any health insurance received via employment will be foregone during the application review period and, even if the application is successful, in the case of SSDI the Medicare waiting period. ${ }^{3}$ Thus, leaving one's job to apply for disability insurance could easily lead to a period of uninsurance that may last months or even years (if the applicant pursues an appeal).

In the example above, the potential gap in insurance coverage arises because the individual's health insurance coverage was tied to his employment status. When a disability onset limits one's ability to work, his health insurance coverage is at risk just when it is most needed. The risk of losing ESHI acts as an implicit incentive to maintain employment as long as possible, thereby inducing “employment lock.” Next, we formalize this intuition by explicitly modeling the role of health insurance in employment and SSDI application decisions.

\section{Conceptual Framework}

To clarify the incentive structure outlined in the previous section and to guide empirical investigation of the relationship between disability onset and

\footnotetext{
${ }^{3}$ COBRA provisions allow for an extended time limit (from 18 months to 29 months) in the event the former employee receives a disability determination from SSA within the first 60 days of continuation coverage.
} 
employment, it is helpful to consider insights from economic theory. An individual who is employed and experiences a work-limiting disability will face four possible discrete states in the future: employed (E), receiving SSDI (D), unemployed and applying for SSDI (A), and unemployed and looking for work (N). ${ }^{4,5}$ Note that the length of the application process-where one must suppress earnings below SGA and may forgo health insurance-is highly variable: approximately four months for an intial determination, yet more than two years on average if the applicant pursues an appeal (Autor et al., 2014). Let $u(t)$ denote flow utility at time $t$ as follows:

$$
u(t)= \begin{cases}w(t)+h(t)-e(t, d) & \text { if } E \\ b(t)+m(t)-g(t) & \text { if } D \\ c(t)+h_{0}(t) & \text { if } A \\ c(t)+h_{0}(t) & \text { if } N\end{cases}
$$

where $w(t)$ represents earnings, $h(t)$ is the value of the individual's health insurance while employed, and $e(t, d)$ is a monetized utility cost of working that captures the cost of exerting effort at work and is a function of the severity of the disability $d$ where $\frac{\partial e(t, d)}{\partial d}>0$. Under SSDI, an individual receives the SSDI benefit payment $b(t)$ and the value of the Medicare coverage $m(t)$ (after the waiting period), but he must pay the monetized utility cost of applying for and participating in SSDI, $g(t)$, which may include stigma, foregone human capital, or other opportunity costs. The flow utility while either applying for SSDI or

\footnotetext{
${ }^{4}$ We frame our discussion around the SSDI program, but an analysis of SSI is qualitatively similar in that applicants' health insurance options are limited during the application process. In our empirical work we cannot distinguish between SSDI or SSI program participation.

${ }^{5}$ We do not consider unemployed and not looking for work as a possible state, although it is possible that the effort cost of work is so high this may be preferable to employment. However, unless the stigma cost of SSDI participation is very high, applying for SSDI dominates unemployment and not searching for work.
} 
searching for a job is the consumption floor $c(t)$ and the value of one's health insurance while unemployed, $h_{0}(t)$.

If we embed this flow utility function in a dynamic lifecycle model of decision making under uncertainty, following Maestas, Mullen and Zamarro (2010), we can derive the expected discounted value of lifetime utility in any state from the present moment forward. This will equal the flow utility plus the expected value of lifetime utility. The expected value of lifetime utility in the future depends on a set of transition probabilities that govern the likelihood of moving from one state to another. Employed individuals separate from their job with probability $q$. Individuals who are applying for SSDI receive a decision from SSA in the current period with probability $x$ and the decision is an allowance with probability a. For unemployed individuals seeking work, job offers arrive with probability $j$. Evaluating the individual's decision problem in this way yields a set of expressions describing the return on lifetime utility in each state. Essentially, lifetime utility pays a rate of return equal to the subjective discount rate $\rho$.

Beginning with the employed state, employment pays a "dividend” at time $t$ equal to $w+h-e$ and there is a probability per unit time $q$ of a "capital loss" associated with job separation $\left(V_{N}-V_{E}\right)$ :

$$
\rho V_{E}=w+h-e+q\left(V_{N}-V_{E}\right) .
$$

In order to apply for SSDI one must leave their current employment. In this case, the individual receives his unemployed flow utility plus the expected capital gain or loss from receiving a response from SSA this period (occurring with probability $x$ ) that is either an allowance (occurring with probability $a$ ) or denial (occurring with probability 1-a):

$$
\rho V_{A}=c+h_{0}+x a\left(V_{D}-V_{A}\right)+x(1-a)\left(V_{N}-V_{A}\right) .
$$


Since we model SSDI participation as an absorbing state, ${ }^{6}$ the return on lifetime utility while receiving SSDI is simply the flow utility $(b+m-g)$ :

$$
\rho V_{D}=b+m-g .
$$

Finally, those unemployed and seeking employment receive the flow utility of unemployment plus the expected capital gain associated with transitioning to employment (occurring with probability $j$ ):

$$
\rho V_{N}=c+h_{0}+j\left(V_{E}-V_{N}\right) .
$$

An employed disabled person will choose to leave employment to apply for SSDI if $V_{A}>V_{E}$. Substituting in equations (1) and (2) and rearranging terms, we see that the individual will leave employment to apply for SSDI if the following expression holds:

$$
(c-w)+\left(h_{0}-h\right)+e+x\left[\left(a V_{D}+(1-a) V_{N}\right)-V_{A}\right]+q\left(V_{E}-V_{N}\right)>0 .
$$

This expression states that an individual will apply for SSDI if the net gain of program application exceeds the net cost. The first three terms comprise the immediate effect of leaving one's employment and applying for SSDI. The first term, $(c-w)$, is the current period net wage loss, the second term, $\left(h_{0}-h\right)$, is the current period net loss (which may be zero) in the value of health insurance and the third term, $e$, represents the current period utility gain from ceasing to exert effort at work. Since $e$ is increasing in impairment severity, we see that individuals with more severe health problems are more likely to apply for SSDI. ${ }^{7}$ The next two terms concern the long run expected capital gains and losses associated with SSDI application. The probability of applying for SSDI is increasing in the promptness of a reply $(x)$, the probability of allowance $(a)$, the

\footnotetext{
${ }^{6}$ In 2012 only 4 percent of SSDI beneficiaries were terminated for medical improvement (3\%) or other reasons such as noncompliance with alcohol/drug abuse treatment programs (Social Security Administration, 2013, Table 50).

${ }^{7}$ More severely impaired individuals may also have greater probabilities of job separation and allowance and may receive quicker decisions than individuals with less severe impairments.
} 
value SSDI benefits $\left(V_{D}\right)$, and the expectation of involuntary job loss $\left(q\left(V_{E}-\right.\right.$ $\left.V_{N}\right)$.

In this paper we focus on the interaction between health insurance and SSDI application. The term of interest is $h_{0}-h$, which is the difference in the flow utility of health insurance while employed $(h)$ versus unemployed $\left(h_{o}\right)$. We assume $h \geq h_{0}$ since employed individuals have the same set of health insurance options as unemployed individuals with the addition (in some cases) of employersponsored health insurance (ESHI), which is only available while employed. We distinguish between two broad scenarios: 1) $h>h_{0}$, and 2) $h \approx h_{0}$. In the first scenario, the value of ESHI is strictly greater than the value of health insurance while unemployed — which may be obtained through a spouse's employer, Medicaid/the government or the purchase of private health insurance or which may be foregone (if $h_{0}=0$ ). In the second scenario, even if ESHI is offered, the individual may elect to receive health insurance through another source which is not tied to his employment. (In the first scenario, revealed preference implies that the individual chooses ESHI when employed.) All else equal, individuals in the first scenario will be less likely to apply for SSDI benefits than individuals in the second scenario.

Table 1 groups individuals into the two scenarios by health insurance type. Note that we distinguish between individuals covered by ESHI with access to health insurance while unemployed through a working spouse whose employer offers ESHI, denoted "ESHI(Spouse)," and individuals with access to spousal coverage, denoted "ESHI only." The former group falls under scenario 2 above and is unlikely to experience substantial "employment lock.” The latter group, on the other hand, may find private coverage extremely costly or may even become uninsured if they were to become unemployed, and therefore would fall under scenario 1 (“employment locked"). Regardless, because they lack the possibility 
of spousal coverage, the net loss in the value of health insurance $h_{0}-h$ is at least as large for individuals with ESHI only compared with individuals with ESHI(Spouse). As a result, the model implies that individuals with ESHI only would be more likely to continue working after the onset of a disability than individuals with other types of health insurance or with ESHI and access to spousal coverage.

\section{Data}

To investigate the relationship between health insurance and labor supply following disability onset, we use data from the nationally representative Health and Retirement Study (HRS), which since 1992 has surveyed individuals aged 51 and older every two years. We use data through 2010. The HRS is an ideal dataset to analyze the events surrounding disability onset because it is longitudinal and enrolls disabled individuals in the panel prospectively (i.e., before they become disabled). As a result, we observe individuals' health insurance and work status both before and after they report onset of a work-limiting health problem. Also important for our analysis, the HRS includes not only the source of one's own health insurance but also the source of one's spouse's coverage.

We define two samples for our analyses. The first sample includes all HRS respondents younger than age 62 who were both working and healthy (i.e., they did not report a work-limiting health problem) in the previous wave (and they did not report a disability at any point in the past). We limit our sample to individuals below age 62 in order to exclude those who are eligible for Social Security retirement benefits. The second sample restricts the first sample to include only those who report a work-limiting health problem (for the first time) in the current wave. Approximately 23 percent of respondents in the first sample report the onset of a work-limiting health problem at some point between 1994 and 2010. We identify disabled individuals based on affirmative answers to the 
question, "Do you have any impairment or health problem that limits the kind or amount of paid work you can do?”8

In addition to information on current and past employment and earnings and health insurance coverage, the HRS contains detailed information on health status, diagnosed medical conditions and functional limitations. The HRS also specifically asks what type of disability is limiting the respondents' ability to work. Table 2 summarizes the types of disabilities reported in our sample and compares our sample with official SSA statistics on SSDI recipients ages 50 and older. Column 1 reports the disabilities of all respondents reporting the onset of a work-limiting health problem, column 2 limits the sample to individuals receiving disability benefits and column 3 reports official figures from SSA. The most common type of disability in both samples and among SSDI recipients is a musculoskeletal impairment, reported by 46 percent of HRS respondents with work-limiting health problems, 39 percent of SSDI recipients in the HRS and 34 percent of SSDI recipients older than 50 nationally. Individuals with circulatory, nervous and endocrine impairments also generally match SSA's official figures.

A notable exception is the category of mental/emotional impairments. Whereas 26 percent of SSDI recipients older than 50 claim benefits due to a mental health problem, only 4 percent of SSDI recipients in the HRS report a mental/emotional impairment. One possibility for the discrepancy is that HRS respondents are reluctant to report mental health as the cause of their disability. Indeed, almost 18 percent of the sample and 13 percent of SSDI recipients in the sample do not report the type of their impairment. However, elsewhere in the

\footnotetext{
${ }^{8}$ One may be concerned that self-reported disability could be endogenous; that is, individuals who are not working (or who successfully claimed DI) are more likely to report that their health limits their ability to work. However, the consensus in the literature is that such justification bias is unlikely to be important in this context (see, e.g., Dwyer and Mitchell, 1999; Benitez-Silva al., 2004).
} 
HRS questionnaire respondents are asked whether a doctor has ever diagnosed them with an emotional, nervous, or psychiatric problem. Here it becomes clear than many more respondents are experiencing mental health problems than was previously evident. Now 20 percent of the disabled sample, and 33 percent of SSDI recipients in the sample, report having a mental or emotional health problem, must closer in alignment to SSA's official estimates.

In addition to impairment type, our conceptual framework suggests that it is important to account for the severity of disability when analyzing post-disability employment outcomes and SSDI application since the cost of exerting effort at work is increasing in severity. To measure (physical) severity, we construct a functional limitations index (FLI) using a series of HRS questions that closely parallel items from SSA's residual functional capacity (RFC) assessment used by disability examiners to evaluate applicants for SSDI and SSI benefits. The RFC assessment contains six sections on limitations: exertional postural, manipulative, visual, communicative and environmental. We identified ten questions from the HRS survey that were analogous to the information in the RFC assessment, listed in Table 3 along with fraction of the sample responding yes to each question in the current or prior wave. We create the index by simply summing the yes responses across each of the 10 questions.

On average individuals report 2.5 physical limitations in the survey wave following the onset of the disability. The most prevalent difficulty is with stooping, kneeling or crouching, experienced by 63 percent of disabled respondents, followed by difficulty pushing or pulling large objects (43 percent), lifting or carrying more than 10 lbs (38 percent) and sitting for two hours or longer (34 percent). On the whole respondents who transition to becoming disabled are less healthy than the average worker in his 50s and early 60s even before they report that their health interferes with their ability to work. The average newly disabled worker reported 1.2 functional limitations in the wave 
prior to onset, compared with an average of 0.7 limitations reported by all workers in any given wave.

Finally, Table 4 presents summary statistics for the disabled sample (persons under age 62 who experience a work limiting disability), overall and by their source of health insurance in the wave prior to disability onset. We divide the sample into seven mutually exclusive health insurance categories. The first two groups include individuals covered by employer-sponsored health insurance (ESHI), either without the option to convert to spousal coverage (denoted "ESHI only”) or with the option of switching to spousal coverage (denoted “ESHI(Spouse)”). Since we cannot distinguish between spousal policies that can or cannot be extended to cover the respondent, we proxy for the option of switching to spousal coverage by whether or not the spouse reports that his or her employer offers ESHI. Nearly 58 percent of the sample was covered by ESHI in the wave prior to disability onset, including (at least) 43 percent of the sample covered by ESHI without the option to switch to spousal coverage and (at most) 15 percent of the sample covered by ESHI but potentially with the option to switch to spousal coverage. These figures are roughly in line with Madrian's (1994) observation that 36 percent of men with ESHI have the option to switch to spousal coverage. The remaining five groups comprise all the other possible health insurance types — coverage through one's spouse (18 percent), private health insurance (5 percent), Medicaid (2 percent) or other government insurance (e.g., VA or Champus; 2 percent)—and no health insurance (15 percent).

On average respondents reporting a work-limiting health problem for the first time in our sample are 55 years old with 12 years of education. Slightly more than half are female, 23 percent are nonwhite and 75 percent are married. The average respondent earned \$2,187 per month prior to disability onset (in 2010 dollars) and average household income was $\$ 4,858$ per month. We link our HRS sample with comprehensive administrative earnings records from SSA and use 
this to compute each individual's average indexed monthly earnings (AIME) based on their earnings history and primary insurance amount (PIA) which is a nonlinear function of the AIME. The PIA gives the SSDI benefit that the individual would be entitled to if he were determined to be disabled according to SSA's definition of disability. The average AIME in our sample is $\$ 1,710$ and the average PIA is just under $\$ 800$, slightly below the average SSDI benefit awarded nationally (\$1,068 in 2010; Social Security Administration, 2013).

Table 4 shows that there are some differences in observable characteristics across the different health insurance types. For example, individuals with ESHI with the option to switch to spousal coverage are slightly younger, more educated and wealthier than individuals with ESHI without a spouse option. (By construction, all of the former group are married, compared with two-thirds of the latter group.) By contrast, those who were previously covered by their spouse's plan in the prior wave include more women and fewer nonwhites and have lower earnings but higher household income than those covered by ESHI without a spouse option. There are no significant differences in impairment severity across the different groups, although the uninsured are less likely to experience the onset of a condition with high expected medical costs (see Section 6.1 for a discussion of which conditions are included in this classification).

The goal of the paper is to estimate the effect of health insurance coverage prior to onset on the probability of remaining employed or transitioning to SSDI after experiencing the onset of a work limiting health problem. A simple comparison of those covered by ESHI with and without a spouse option shows there are no statistically significant differences in post-onset outcomes. On the other hand, consistent with the "employment lock” hypothesis, individuals with spousal coverage are less likely to apply for and receive SSDI. Table 4 also shows that Medicaid beneficiaries and the uninsured are less likely to work post-onset and more likely to apply for SSDI than those covered by ESHI. Any simple 
comparison of means, however, is potentially confounded by observable and unobservable factors. In the next section we outline our strategy for estimating the effects of various health insurance types on labor supply outcomes and testing the employment lock hypothesis in particular.

\section{Empirical Strategy}

As described above, the goal of the paper is to estimate the effect of different health insurance types on remaining employed and claiming SSDI benefits following the onset of a work-limiting health problem. Specifically, we wish to test whether individuals with ESHI are more likely to continue working in order to retain their health insurance than those with affordable health insurance options that are not tied to employment status. Since health insurance types are not randomly assigned to individuals, however, there may be significant unobserved differences between people with different health insurance plans. Selection into health insurance plans may reflect differences in health or other factors that influence one's probability of working in any given period. For instance, individuals with lower effort costs of work on average may select into jobs that offer health insurance since these jobs typically require more hours per week.

We employ two complementary strategies to estimate the effect of health insurance on labor supply outcomes. The first strategy makes use of both healthy and disabled workers to estimate and control for pre-onset differences in propensity to continue working by health insurance status. We estimate the following equation:

$$
y_{i}=X_{i} \beta+\sum_{j=2}^{7}\left[\gamma_{0 j} H I_{i}^{j}+\gamma_{1 j} D_{i} * H I_{i}^{j}\right]+\varepsilon_{i}
$$


where $y_{i}$ is an indicator of employment status, $X_{i}$ is a vector of control variables (including past earnings, potential SSDI benefit (PIA), the functional limitations index in the current and prior waves, age, age squared, education, wealth, gender, race, marital status and a dummy variable for self-employment), $H I_{i}^{j}$ is an indicator for whether individual $i$ had health insurance type $j$ in the prior wave where ESHI is the omitted category, $D_{i}$ is an indicator for whether the respondent reports a work-limiting health impairment in the current wave and $\varepsilon_{i}$ are unobserved factors that influence one's propensity to work. The coefficients $\gamma_{0 j}$ capture pre-existing differences in unobserved factors by health insurance status and $\gamma_{1 j}$ are estimates of the effect of health insurance type $j$ on the probability of continuing to work post-onset relative to individuals with ESHI.

The above approach is limited in that it only allows us to examine employment outcomes (since healthy respondents cannot claim SSDI) and we cannot examine interactions between health insurance and severity or type of impairment. Therefore, we employ a second strategy that focuses on disabled respondents only and includes a rich set of control variables including functional limitation index in the current wave and past earnings (AIME) to proxy for differences in health and preferences for work across the different health insurance types. We estimate equations of the form:

$$
y_{i}=X_{i} \beta+\sum_{j=2}^{7} \gamma_{1 j} H I_{i}^{j}+\varepsilon_{i}
$$

where $y_{i}$ is the outcome of interest (now, employment, SSDI application or SSDI receipt) and the other variables are as defined above (note now $D_{i}=1$ for all individuals in the sample and $X_{i}$ includes variables previously missing in equation (3) describing the current health impairment). 
To test the hypothesis that employment lock exists for individuals with ESHI and no spousal option, we consider two comparison groups: individuals with ESHI and potential access to spousal health insurance coverage (denoted “ESHI(Spouse)”) and individuals currently covered by spousal coverage. The first comparison group may be influenced somewhat by employment lock since revealed preference implies some loss in the utility value of health insurance if ESHI is lost (see the discussion in Section 3). The second group should not be influenced by employment lock since there is no difference in health insurance in employed and unemployed states. Therefore we expect to estimate a larger coefficient on spousal coverage than ESHI(Spouse) all else equal. Since ESHI only is the omitted category in the regressions, we find evidence of employment lock if we cannot reject $\gamma_{1 j}<0$ in regressions where employment is the outcome and $\gamma_{1 j}>0$ where SSDI application or claiming is the outcome.

\section{Results}

\subsection{Effect of Source of Health Insurance Coverage on Employment}

In this section we estimate the effect of health insurance type on continued employment following the onset of a work-limiting health condition. Table 5 presents estimates of equation (3) using information on both healthy and newly disabled individuals who were working in the previous wave. Columns 1 and 2 present estimates for the entire sample and for a married subsample, respectively. As expected standard errors are larger for the married subsample, but the estimated effect sizes are comparable for both groups. Ninety percent of the sample is still working in the next wave, but not surprisingly those who experience the onset of a work-limiting disability are significantly less likely to be employed. We find that disability onset lowers an individual's probability of work by 30 percentage points. 
As discussed in the previous section, by including both healthy and disabled individuals we can account for differences in labor force attachment by health insurance type. Since the omitted category is ESHI, the coefficients on each of the uninteracted health insurance types allows us to compare differences in work propensity between each health insurance type and ESHI directly. We find that individuals who are covered by ESHI but who could obtain health insurance through a spouse are not significantly more or less likely to work than those covered by ESHI without the spousal insurance option. On the other hand, even controlling for differences in observable factors, those who are actually covered by their spouse's plan are three percentage points less likely to work than those covered by ESHI without a spouse option. These results suggest that the ESHI(Spouse) group may be a better comparison group for the ESHI group than the group actually receiving spousal coverage. Not surprisingly, we also find that the uninsured, individuals with private health insurance and those with Medicaid or other government insurance are significantly less attached to the labor force than individuals covered by ESHI.

We now turn to estimating the effect of health insurance type on the probability of remaining employed following disability onset. As discussed in Section 3, our theory predicts that, all else being equal, the ESHI only group has the largest incentive to continue employment following a disability because they are potentially “employment locked.” Therefore, we expect all other groups to be less likely to work relative to the ESHI only group following disability onset. However, the estimates on the interaction between disability onset and health insurance type do not suggest employment lock plays a significant role in postonset employment outcomes. We find no statistically significant differences in employment following disability onset between the ESHI only and ESHI(Spouse) groups or between the ESHI only and spousal coverage groups (in fact, the estimated coefficient on Spouse* $\mathrm{D}$ is the wrong sign). An exception is that 
individuals with Medicaid prior to onset are 20 percentage points less likely to be employed following a disability onset than individuals with ESHI.

Bradley et al. (2012) speculate that, for whatever reason, men do not see their wives' employers as a viable source of health insurance. We investigate this assertion by estimating equation (3) separately by gender, presented in columns 34 of Table 5. We do not find evidence that employment lock is stronger for women than for men. Indeed, we estimate a negative coefficient on ESHI(Spouse) for men but not for women, although both estimates are imprecise and statistically insignificant. Interestingly, we find that the effect of Medicaid is driven by women (recall from Table 4 that 64 percent of newly disabled previous Medicaid beneficiaries are women).

The absence of a finding of employment lock is somewhat surprising given the widespread evidence of employment lock elsewhere in the literature. One reason for the lack of effect in this context is that many individuals who become disabled may be physically or mentally unable to work; i.e., the unobserved effort cost of work is so large that other factors do not impact the work decision. Another reason is that the value of health insurance may be low for some conditions with inexpensive treatment options. Yet, for individuals experiencing the onset of a condition with very high expected costs (e.g., cancer) continued health insurance coverage is extremely valuable.

In order to examine heterogeneity in the effect of health insurance on employment following the onset of a disability, we limit the sample to newly disabled individuals only. Table 6 presents the estimates of equation (4) where the outcome is employment in the wave following disability onset. Column 1, estimated on the entire disabled sample, reproduces our previous finding that there appears to be little evidence in favor of the employment lock hypothesis (although now both coefficients on ESHI(Spouse) and Spouse are the correct sign). Column 2 limits the sample to individuals experiencing the onset of a low 
severity disability, defined by no increase in the functional limitations index from prior to current wave. The estimated effect sizes roughly triple in magnitude but the standard errors also double and the estimates are still statistically indistinguishable from zero.

Finally, column 3 further limits the sample to individuals with conditions that are both low severity and high expected cost. In order to identify high cost conditions we use a list compiled by Druss et al. (2002) on the most expensive medical conditions in America. Five of the top ten most expensive impairments (ischemic heart disease, congestive heart failure, cardiac dysrhythmias, mood disorders, and back problems) correspond to a condition type defined in HRS. ${ }^{9}$ Based on this list we categorize heart/circulatory, musculoskeletal, and emotional conditions as high cost. We also include cancer as a high cost condition because researchers have previously found evidence of employment lock among those diagnosed with cancer (Bradley et al. 2012, Tunceli et al. 2009). Finally, even though the sample size is limited, evidence of employment lock emerges, as we find that individuals covered by ESHI but with access to spousal insurance are 16 percentage points (23 percent) less likely to work following the onset of a low severity, high cost condition than individuals with ESHI only. However, we still do not find a statistically significant difference between individuals with ESHI and those with spousal coverage, even though our earlier analysis suggests that the estimated effect of spousal coverage could be overstated since all else equal those with spousal coverage are less likely to work than those with ESHI regardless of health status. Interestingly, the Medicaid effect seems to have been completely driven by individuals with higher severity and/or low cost conditions.

\footnotetext{
${ }^{9}$ The other five of the top ten most expensive were respiratory malignancies, cerebrovascular disease, peripheral vascular disorders, diabetes and motor vehicle accidents. These five types have no direct analogs in the categories defined by the HRS.
} 


\subsection{Effect of Source of Health Insurance Coverage on SSDI Application and Claiming}

Our theoretical framework assumes that once employed individuals become disabled they choose between continuing to work and leaving the labor force to apply for disability insurance benefits, which dominates becoming unemployed and not seeking work unless the stigma cost of SSDI participation is extraordinarily high. Table 7 presents estimates of the effect of different health insurance types on applying for SSDI within four years (two HRS survey waves) of disability onset. Employment lock should manifest itself in positive coefficients now, since all else equal individuals with ESHI should be less likely to apply for SSDI than individuals with spousal coverage or the option of switching to spousal coverage. Instead, we estimate negative effects of spousal coverage, although for the most part they are not statistically significant. Columns 1-3 present estimates for all newly disabled individuals, the subset of those with low severity impairments and the further subset of those with low severity and high cost impairments, respectively. Whereas we found evidence of employment lock among individuals with low severity/high cost conditions, we do not find support for the idea that the "locked" individuals would apply for disability benefits if they did not stand to lose their health insurance coverage.

Interestingly, we do find evidence of a tradeoff between working and applying for SSDI among Medicaid beneficiaries. Whereas Medicaid beneficiaries are 33 percentage points less likely than those with ESHI to continue working following disability onset (including 12.5 percentage points due to selection on unobservables; see Table 5), they are 17 percentage points more likely to apply for SSDI. Thus about half of Medicaid beneficiaries who drop out of the labor force following disability onset do so to apply for SSDI even though they already have health insurance. (Recall the regressions control for potential DI benefit, or PIA, so the financial incentive to apply for SSDI in order to receive 
cash benefits is held fixed.) We cannot, however, separate out how much of the increased SSDI claiming among Medicaid beneficiaries is due to selection and how much is due to Medicaid receipt itself.

There are a number of reasons why Medicaid beneficiaries may be more likely to apply for SSDI benefits aside from differences in unobserved preferences for social insurance. For example, Medicaid participation may confer better familiarity with government assistance programs in general resulting in lower stigma and/or application costs. Another intriguing possibility is that states may encourage Medicaid beneficiaries who become disabled to apply for SSDI benefits in order to shift costs to the federal level. ${ }^{10}$ Finally, columns 4-6 present estimates of the effect of health insurance on SSDI receipt within four years of disability onset and finds that fewer than half of the "induced" applications from Medicaid beneficiaries are ultimately successful. Indeed, despite the increased application rate Medicaid beneficiaries are not statistically any more likely to receive SSDI than those with ESHI.

\section{Conclusion}

Our findings indicate that, although not universally important for individuals with work-limiting health conditions, employment lock does play a role for the 20 percent of individuals with disabilities that are not severely physically limiting but that are likely to be costly in terms of expected medical treatment. We do not find that ESHI reduces disability insurance application or receipt. With the passage of the ACA there has been concern that SSDI applications may swell because the incentive to remain employed will diminish for disabled workers reliant on ESHI. Our results suggest that the availability of

\footnotetext{
${ }^{10}$ Maestas, Mullen and Strand (2014) find suggestive evidence that counties with low health insurance rates prior to the 2006 Massachusetts health insurance reform may have responded by encouraging new SSDI applications from the long term unemployed.
} 
non-employment-based health insurance may cause disabled individuals with high cost/low severity conditions to leave the workforce but it will not necessarily lead to increased disability insurance application among individuals who formerly had ESHI. 


\section{References}

Autor, David, Nicole Maestas, Kathleen J. Mullen and Alexander Strand (2014).

"Does Delay Cause Decay? Administrative Decision Time and the Employment and Earnings of Social Security Disability Applicants.” Manuscript.

Baicker, Katherine, Amy Finkelstein, Jae Song and Sarah Taubman (2014). “The Impact of Medicaid on Labor Force Activity and Program Participation: Evidence from the Oregon Health Insurance Experiment.” American Economic Review Papers \& Proceedings, 104(5), pp. 322-328.

Benitez-Silva, Hugo, Moshe Buchinsky, Hui Man Chan, Sofia Cheidvasser and John Rust (2004). "How large is the bias in self-reported disability?” Journal of Applied Econometrics, 19, pp. 649-270.

Board of Trustees, Federal Old-Age and Survivors Insurance and Federal Disability Insurance Trust Funds (2013). “The 2013 Annual Report of the Board of Trustees of the Federal Old-Age and Survivors Insurance and Federal Disability Insurance Trust Funds.” Accessed on 12/17/13 at http://www.socialsecurity.gov/OACT/TR/2013/tr2013.pdf.

Bradley, Cathy J., David Neumark, and Scott Barkowski (2013). “Does employerprovided health insurance constrain labor supply adjustments to health shocks? New evidence on women diagnosed with breast cancer.” Journal of Health Economics, 32, pp. 833-849.

Bradley, C.J., D. Neumark, Z. Luo and H. Bednarek (2006). "Employment-based health insurance, illness, and labor supply of women: evidence from married women with breast cancer.” Health Economics, 16(7), pp. 719734.

Bradley, Cathy J., David Neumark, and Meryl Motika (2012). “The effects of health shocks on employment and health insurance: the role of employerprovided health insurance.” International journal of health care finance and economics 12(4), pp. 253-267.

Buchmueller, T. C. Carey and HG. Levy (2013). "Will employers drop health insurance coverage because of the Affordable Care Act?” Health Affairs, 32(9), pp. 1522-1530.

Congressional Budget Office (2014). "Labor Market Estimates of the Affordable Care Act.” Appendix C in The Budget and Economic Outlook: 2014 to 2024. Accessed on 8/15/14 at http://www.cbo.gov/publication/45010.

Druss, B. G., Marcus, S. C., Olfson, M., \& Pincus, H. A. (2002). "The most expensive medical conditions in America”. Health Affairs, 21(4), pp. 105111.

Finkelstein, Amy, Sarah Taubman, Bill Wright, Mira Bernstein, Jonathan Gruber, Joseph P. Newhouse, Heidi Allen, Katherine Baicker and the Oregon 
Health Study Group (2012). “The Oregon Health Insurance Experiment: Evidence from the First Year.” Quarterly Journal of Economics, 127(3), pp. 1057-1106.

Garthwaite, Craig, Tal Gross and Matthew J. Notowidigdo (2014). "Public Health Insurance, Labor Supply, and Employment Lock.” Quarterly Journal of Economics, 129(2), pp. 653-696.

Gruber, Jonathan and Brigitte C. Madrian (2004). "Health Insurance, Labor Supply and Job Mobility : A Critical Review of the Literature.” in McLaughlin, Catherine (ed.) Health Policy and the Uninsured. Washington, D.C.: Urban Institute Press.

Madrian, Brigette (1994). "Employment-based health insurance and job mobility: Is there evidence of job lock?” Quarterly Journal of Economics, 109(10, pp. 27-54.

Maestas, Nicole, Kathleen Mullen and Alexander Strand (2013). “Does Disability Insurance Receipt Discourage Work? Using Examiner Assignment to Estimate Causal Effects of SSDI Receipt.” American Economic Review, 103(5), pp. 1797-1829.

Maestas, Nicole, Kathleen J. Mullen and Alexander Strand (2014). “Disability Insurance and Healthcare Reform: Evidence from Massachusetts.” American Economic Review Papers \& Proceedings, 104(5), pp. 329-335..

Maestas, Nicole, Kathleen J. Mullen, and Gema Zamarro (2010). "Research Designs for Estimating Induced Entry into the SSDI Program Resulting from a Benefit Offset.” RAND Technical Report TR-908-SSA.

Maestas, Nicole and Julie M. Zissimopoulos (2010). "How Longer Work Lives Ease the Crunch of Population Aging" Journal of Economic Perspectives, 24(1), pp. 139-160.

Social Security Administration (2013). Annual Statistical Report on the Social Security Disability Insurance Program, 2012. Accessed on 12/3/13 at http://www.ssa.gov/policy/docs/statcomps/di_asr/.

Tunceli, K., Short, P. F., Moran, J. R., \& Tunceli, O. (2009) “Cancer survivorship, health insurance, and employment transitions among older workers.” Inquiry, 46(1), pp. 17-32. 
Figure 1

Health Insurance Options After Disability Onset

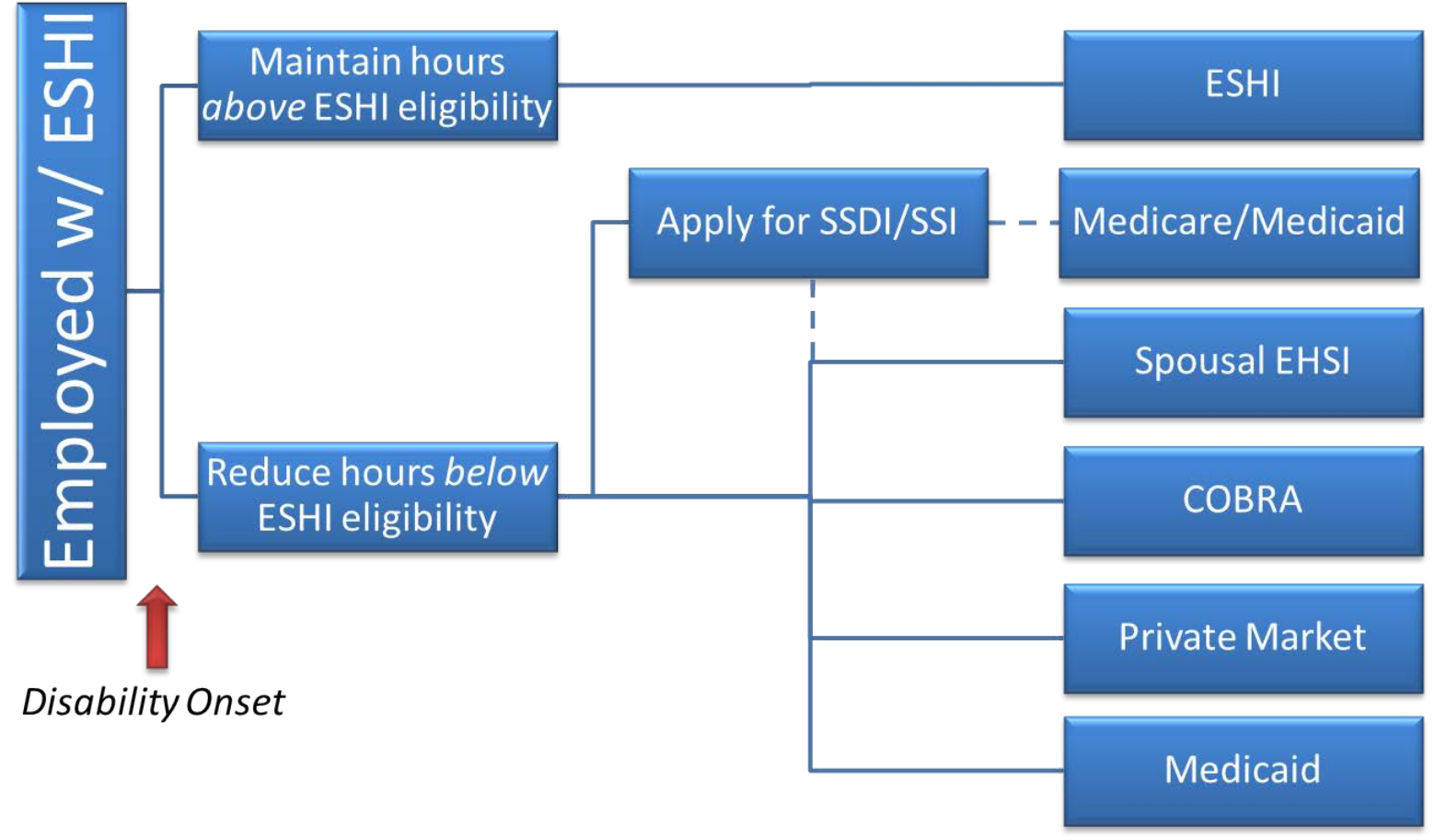




\begin{tabular}{l|l}
\hline \hline Table 1. Classification of insurance types into model scenarios \\
\hline Scenario & $\begin{array}{l}\text { Current source of health insurance } \\
\text { (while employed) }\end{array}$ \\
\hline Facing employment lock $\left(h>h_{0}\right)$ & ESHI only \\
\hline Not facing employment lock $\left(h \approx h_{0}\right)$ & ESHI(Spouse) \\
& Spouse \\
& Private \\
& Medicaid \\
& Other government \\
& None/uninsured \\
\hline \hline
\end{tabular}

Note: See Section 3 for more details. 
Table 2. Distribution of Impairment Types

\begin{tabular}{lrrr}
\hline \hline $\begin{array}{l}\text { Health Condition Causing the } \\
\text { Impairment or Problem }\end{array}$ & $\begin{array}{c}\text { HRS Work-Limited } \\
\text { Sample }\end{array}$ & $\begin{array}{c}\text { Subsample Receiving } \\
\text { SSDI }\end{array}$ & $\begin{array}{c}\text { SSA Official Statistics } \\
\text { (Ages 50+) }\end{array}$ \\
\hline Musculoskelatal & 46.1 & 39.2 & 34 \\
Circulatory & 11.3 & 16.1 & 11 \\
Nervous & 5.4 & 6.8 & 9 \\
Endocrine & 2.8 & 4.5 & 4 \\
Mental/Emotional & 1.4 & 4.2 & 26 \\
Other & 15.3 & 16.1 & 18 \\
Don't Know/Refused & 17.7 & 12.9 & -- \\
\hline Psychological Problems Reported & 20.0 & 32.9 & -- \\
\hline \hline
\end{tabular}

Source: Authors' calculations for columns 1-2; Social Security Administration (2011) for column 3. 
Table 3: Sample Means of Items Comprising Functional Limitations Index

\begin{tabular}{lccc}
\hline \hline & \multicolumn{2}{c}{ Work-Limited Sample } & \\
Item & Onset Wave & Prior Wave & Whole Sample \\
\hline Some difficulty lift/carry 10 lbs & 0.377 & 0.143 & 0.074 \\
Some difficulty pushing/ pulling large object & 0.434 & 0.168 & 0.098 \\
Some difficulty picking up a dime & 0.084 & 0.036 & 0.020 \\
Some difficulty stooping/kneeling/crouching & 0.627 & 0.410 & 0.255 \\
Some difficulty reaching/extending arms up & 0.250 & 0.107 & 0.066 \\
Some difficulty walking across a room & 0.074 & 0.014 & 0.008 \\
Some difficulty sitting for 2hours & 0.344 & 0.201 & 0.115 \\
Some difficulty climbing 1 flight of stairs & 0.233 & 0.094 & 0.045 \\
Visual impairment & 0.051 & 0.025 & 0.014 \\
Hearing impairment & 0.033 & 0.022 & 0.015 \\
\hline Sum (Functional Limitations Index) & 2.487 & 1.227 & 0.708 \\
\hline \hline
\end{tabular}


Table 4. Summary Statistics for Work-Limited Sample by Source of Health Insurance Prior to Onset of Work Limitation

\begin{tabular}{|c|c|c|c|c|c|c|c|c|}
\hline \multirow[b]{2}{*}{ Variable } & \multirow[b]{2}{*}{ All } & \multicolumn{7}{|c|}{ Source of Health Insurance } \\
\hline & & ESHI Only & ESHI(Spouse) & Spouse & Private & Medicaid & $\begin{array}{l}\text { Other Gov. } \\
\text { (e.g., Tricare) }\end{array}$ & None \\
\hline \multirow[t]{2}{*}{ Age } & 54.7 & 55.3 & $54.4 * * *$ & $53.8^{* * *}$ & 55.6 & $52.7^{* * *}$ & 54.3 & $54.1^{* * *}$ \\
\hline & $(4.25)$ & $(3.87)$ & $(4.17)$ & $(4.73)$ & $(3.38)$ & $(4.75)$ & $(4.35)$ & $(4.63)$ \\
\hline \multirow[t]{2}{*}{ Years of Education } & 12.3 & 12.6 & $13.1 * * *$ & 12.5 & 12.9 & $10.4^{* * *}$ & 12.7 & $10.5^{* * *}$ \\
\hline & $(2.97)$ & $(2.80)$ & $(2.46)$ & $(2.50)$ & $(2.53)$ & $(3.75)$ & $(2.40)$ & $(3.74)$ \\
\hline$\%$ Female & 54 & 49 & 50 & $70 * * *$ & 56 & $64 * *$ & 40 & $56 * *$ \\
\hline \% Nonwhite & 23 & 22 & 23 & $17^{*}$ & $14^{* *}$ & $45^{* * *}$ & 29 & $31 * * *$ \\
\hline \%Married/ Partnered & 75 & 62 & $99 * * *$ & $98 * * *$ & $71^{*}$ & 51 & 69 & $67^{*}$ \\
\hline \multirow[t]{2}{*}{ Earnings } & 2187 & 2933 & 2752 & $1448 * * *$ & $1130 * * *$ & $816 * * *$ & $1653 * * *$ & $971 * * *$ \\
\hline & (2289) & (2499) & $(2356)$ & (1806) & (1328) & (1241) & (2043) & $(1245)$ \\
\hline \multirow[t]{2}{*}{ Household Income } & 4858 & 4710 & $6848 * * *$ & $5,932 * * *$ & 4139 & $1922 * * *$ & 4280 & $2680 * * *$ \\
\hline & (4658) & (4471) & (5479) & (4261) & (4028) & (2354) & (3340) & $(4156)$ \\
\hline \multirow[t]{2}{*}{ AIME } & 1710 & 2150 & 2067 & $1230 * * *$ & $1343^{* * *}$ & $717^{* * *}$ & $1347 * * *$ & $933 * * *$ \\
\hline & (1325) & $(1362)$ & (1344) & (1118) & (988) & $(760)$ & (1060) & (890) \\
\hline \multirow[t]{2}{*}{ PIA } & 792 & 941 & 915 & $627^{* * *}$ & $684 * * *$ & $423 * * *$ & $671 * * *$ & $525 * * *$ \\
\hline & $(451)$ & $(430)$ & $(446)$ & $(418)$ & $(368)$ & $(350)$ & $(385)$ & $(364)$ \\
\hline \multirow[t]{2}{*}{ FLI (pre-onset) } & 1.29 & 1.35 & 1.3 & 1.25 & $1.00^{*}$ & 1.53 & 0.96 & 1.21 \\
\hline & $(1.46)$ & $(1.52)$ & $(1.48)$ & $(1.37)$ & $(1.20)$ & $(1.85)$ & $(1.24)$ & $(1.39)$ \\
\hline \multirow[t]{2}{*}{ FLI increase (pre- to post-onset) } & 1.18 & 1.19 & 0.95 & 1.12 & 1.34 & 1.41 & 1.23 & 1.44 \\
\hline & $(2.00)$ & $(1.93)$ & $(1.94)$ & $(2.06)$ & $(1.98)$ & $(2.56)$ & $(1.72)$ & $(2.14)$ \\
\hline \% Low Severity (no increase in FLI) & 43 & 42 & 48 & 44 & 47 & 48 & 41 & 36 \\
\hline$\%$ Low Severity/High Cost & 33 & 35 & 35 & 33 & 32 & 43 & 33 & $23 * * *$ \\
\hline$\%$ Working within 2 Years of Onset & 58 & 59 & 60 & 60 & 62 & $26 * * *$ & 52 & $52 * *$ \\
\hline$\%$ Applied for SSDI Within 2 Years of Onset & 28 & 29 & 26 & $21 * * *$ & $21^{*}$ & $50 * * *$ & 29 & $36 * * *$ \\
\hline$\%$ Applied for SSDI Within 4 Years of Onset & 30 & 30 & 28 & $23 * * *$ & 24 & $53 * * *$ & 29 & $39 * * *$ \\
\hline$\%$ Received SSDI Within 4 Years of Onset & 20 & 21 & 18 & $15^{* *}$ & $14.5^{*}$ & 27.5 & $11^{*}$ & 20 \\
\hline No. Observations & 2230 & 966 & 324 & 409 & 118 & 42 & 47 & 324 \\
\hline$\%$ of Sample & $100 \%$ & $43 \%$ & $15 \%$ & $18 \%$ & $5 \%$ & $2 \%$ & $2 \%$ & $15 \%$ \\
\hline
\end{tabular}

Notes: ${ }^{*}$ significant at $10 \%$ level, ${ }^{* *}$ significant at $5 \%$ level, ${ }^{* * *}$ significant at $1 \%$ level: t-tests of differences between ESHI and other sources of health insurance, respectively. 
Table 5. The Effect of Health Insurance Source in Prior Wave on Current Employment, All Workers

\begin{tabular}{|c|c|c|c|c|}
\hline & (1) & $(2)$ & (3) & (4) \\
\hline & Overall & Married & Men & Women \\
\hline \multirow[t]{2}{*}{ Disabled in Current Wave } & $-.307 * * *$ & $-.292 * * *$ & $-.295 * * *$ & $-.314 * * *$ \\
\hline & $(.019)$ & $(.023)$ & $(.026)$ & $(.026)$ \\
\hline \multirow[t]{2}{*}{ ESHI(Spouse) } & -.001 & .000 & .011 & -.010 \\
\hline & $(.005)$ & $(.006)$ & $(.008)$ & $(.007)$ \\
\hline \multirow[t]{2}{*}{ Spouse } & $-.031 * * *$ & $-.029 * * *$ & .0001 & $-.042 * * *$ \\
\hline & $(.006)$ & $(.006)$ & $(.009)$ & $(.008)$ \\
\hline \multirow[t]{2}{*}{ Private } & $-.021 * *$ & $-.025^{* *}$ & .013 & $-.038 * * *$ \\
\hline & $(.010)$ & $(.012)$ & $(.013)$ & $(.014)$ \\
\hline \multirow[t]{2}{*}{ Medicaid } & $-.125^{* * *}$ & $-.123 * *$ & $-.120 *$ & $-.130 * * *$ \\
\hline & $(.039)$ & $(.050)$ & $(.066)$ & $(.047)$ \\
\hline \multirow[t]{2}{*}{ Other Gov. } & $-.063 * * *$ & $-.069 * * *$ & -.044 & $-.075 * *$ \\
\hline & $(.023)$ & $(.026)$ & $(.029)$ & $(.031)$ \\
\hline \multirow[t]{2}{*}{ None } & $-.027 * * *$ & $-.030 * * *$ & .007 & $-.050 * * *$ \\
\hline & $(.008)$ & $(.009)$ & $(.012)$ & $(.011)$ \\
\hline \multirow[t]{2}{*}{ Disabled*ESHI(Spouse) } & -.008 & -.011 & -.040 & .053 \\
\hline & $(.036)$ & (.039) & $(.052)$ & $(.049)$ \\
\hline \multirow[t]{2}{*}{ Disabled*Spouse } & .036 & .020 & .074 & .025 \\
\hline & $(.033)$ & $(.036)$ & $(.058)$ & $(.042)$ \\
\hline \multirow[t]{2}{*}{ Disabled*Private } & .040 & .032 & .061 & .019 \\
\hline & $(.054)$ & $(.065)$ & $(.081)$ & $(.072)$ \\
\hline \multirow[t]{2}{*}{ Disabled*Medicaid } & $-.200 * *$ & -.169 & -.027 & $-.294 * * *$ \\
\hline & $(.083)$ & $(.121)$ & $(.153)$ & $(.092)$ \\
\hline \multirow[t]{2}{*}{ Disabled*Other Gov. } & -.057 & -.100 & -.070 & -.047 \\
\hline & $(.082)$ & $(.097)$ & $(.114)$ & $(.126)$ \\
\hline \multirow[t]{2}{*}{ Disabled*None } & -.030 & -.032 & -.047 & -.017 \\
\hline & $(.037)$ & $(.046)$ & $(.056)$ & $(.050)$ \\
\hline Mean Dep. Var. & 0.88 & 0.89 & 0.89 & 0.88 \\
\hline $\mathrm{N}$ & 23652 & 19068 & 9864 & 13788 \\
\hline \multicolumn{5}{|c|}{$\begin{array}{l}\text { Notes: }{ }^{*} \text { significant at } 10 \% \text { level, }{ }^{* *} \text { significant at } 5 \% \text { level, }{ }^{* * *} \text { significant at } 1 \% \text { level. Standard } \\
\text { errors clustered at the household level. Omitted category for health insurance types is ESHI } \\
\text { only. Other controls include past earnings, potential SSDI benefit (PIA), FLI in current and prior } \\
\text { waves, age, age squared, education, wealth, gender, race, marital status and self-employment } \\
\text { status. }\end{array}$} \\
\hline
\end{tabular}


Table 6. The Effect of Pre-Disability Health Insurance Source on Employment Post Disability Onset, Newly Disabled Workers

\begin{tabular}{lccc}
\hline \hline & $(1)$ & $(2)$ & $\begin{array}{c}(3) \\
\text { Low Severity/ } \\
\text { High Cost }\end{array}$ \\
\hline ESHI(Spouse) & Overall & Low Severity & $-.160^{* *}$ \\
Spouse & -.028 & -.088 & $(.078)$ \\
Private & $(.037)$ & $(.063)$ & -.073 \\
& -.035 & -.098 & $(.080)$ \\
Medicaid & $(.036)$ & $(.067)$ & 0.063 \\
& 0.001 & -.009 & $(.068)$ \\
Other Gov. & $(.056)$ & $(.107)$ & -.019 \\
& $-.329 * * *$ & -.141 & $(.159)$ \\
None & $(.072)$ & $(.139)$ & .115 \\
& -.134 & .150 & $(.171)$ \\
FLI & $(.082)$ & $(.137)$ & -.088 \\
& -.029 & -.007 & $(.095)$ \\
\hline Mean Dep. Var. & $(.040)$ & $(.072)$ & -.034 \\
\hline $\mathrm{N}$ & $-.069 * * *$ & -.035 & $(.032)$ \\
\hline \hline
\end{tabular}

Notes: * significant at $10 \%$ level, ${ }^{* *}$ significant at $5 \%$ level, ${ }^{* * *}$ significant at $1 \%$ level. Standard errors clustered at the household level. Omitted category for health insurance types is ESHI only. Other controls include past earnings, potential SSDI benefit (PIA), FLI in current and prior waves, age, age squared, education, wealth, gender, race, marital status and self-employment status. 
Table 7. The Effect of Health Insurance Source on SSDI Application and Claiming

\begin{tabular}{|c|c|c|c|c|c|c|}
\hline & (1) & (2) & (3) & (4) & (5) & (6) \\
\hline & \multicolumn{3}{|c|}{ Applied for SSDI Within 4 Years } & \multicolumn{3}{|c|}{ Received SSDI Within 4 Years } \\
\hline & & & Low Severity/ & & & Low Severity/ \\
\hline & Overall & Low Severity & High Cost & Overall & Low Severity & High Cost \\
\hline \multirow[t]{2}{*}{ ESHI(Spouse) } & -.010 & $-.100^{*}$ & -.032 & -.032 & $-.100 * *$ & -.081 \\
\hline & $(.035)$ & $(.052)$ & $(.070)$ & $(.031)$ & $(.041)$ & $(.055)$ \\
\hline \multirow[t]{2}{*}{ Spouse } & -.014 & .045 & -.060 & -.027 & .077 & .114 \\
\hline & $(.036)$ & $(.068)$ & $(.085)$ & $(.031)$ & $(.061)$ & $(.078)$ \\
\hline \multirow[t]{2}{*}{ Private } & -.017 & $-.113^{*}$ & -.060 & -.039 & -.046 & -.002 \\
\hline & $(.050)$ & $(.065)$ & $(.091)$ & $(.043)$ & $(.061)$ & $(.083)$ \\
\hline \multirow[t]{2}{*}{ Medicaid } & $.170 * *$ & .041 & -.104 & .066 & .035 & .081 \\
\hline & $(.085)$ & $(.129)$ & $(.131)$ & $(.075)$ & $(.110)$ & $(.148)$ \\
\hline \multirow[t]{2}{*}{ Other Gov. } & -.029 & -.066 & -.000 & -.081 & $-.138 * * *$ & $-.139 * * *$ \\
\hline & $(.072)$ & $(.130)$ & (.169) & $(.054)$ & $(.043)$ & $(.060)$ \\
\hline \multirow[t]{2}{*}{ None } & $.085^{* *}$ & .085 & .110 & -.000 & .007 & .019 \\
\hline & $(.040)$ & $(.077)$ & $(.100)$ & $(.036)$ & $(.063)$ & $(.082)$ \\
\hline \multirow[t]{2}{*}{ FLI } & $.050 * * *$ & $.060 * * *$ & $.074 * * *$ & $.062 * * *$ & $.038^{* *}$ & .038 \\
\hline & $(.007)$ & $(.021)$ & $(.028)$ & $(.007)$ & (.019) & $(.025)$ \\
\hline Mean Dep. Var & 0.31 & 0.18 & 0.18 & 0.20 & 0.13 & 0.14 \\
\hline $\mathrm{N}$ & 1548 & 419 & 290 & 1540 & 417 & 289 \\
\hline
\end{tabular}

